УДК 616.34-007.43-031:611.957-059-089.83

DOI 10.11603/2414-4533.2016.3.6807

(C) М. Ю. КРЕСТЯНОВ

Національна академія післядипломної освіти ім. П. Л. Шупика

\title{
Міні-інвазивні способи лікування пахвинних гриж
}

\author{
M. YU. KRESTIANOV \\ P. Shupyk National Medical Academy of Postgraduate Education
}

\section{MINIMALLY INVASIVE TECHNIQUES OF INGUINAL HERNIA REPAIR}

Вибір малоінвазивного підходу до лікування пахвинних гриж на сьогодні залишається спірним питанням. Дві найпоширеніші техніки - лапароскопічна трансабдомінальна преперитонеальна пластика (ТАРР) та тотальна екстраперитонеальна пластика (ТЕР), при яких сітчастий імплант встановлюється в преперитонеальний простір для повного перекриття слабких місць пахвинної ділянки, не відрізняються за рівнем рецидивів, але мають певні відмінності за тривалістю операції, кривою навчання, рівнем інтра- та післяопераційних ускладнень, вартістю втручання. Порівняння вищеназваних технік дає можливість визначити оптимальну тактику з урахуванням індивідуальних особливостей конкретного пацієнта.

\begin{abstract}
A choice of minimally invasive approach to the inguinal hernia repair still remains controversial. The two most common techniques, transabdominal preperitoneal plasty (TAPP) and the totally extraperitoneal (TEP) plasty, in which a mesh is placed in the preperitoneal space to cover the entire myopectineal orifice, do no differ significantly in recurrence rate but show certain differences regarding the operation time, learning curve, rate of intra- and postsurgical complications, and costs. A comparison of mentioned techniques allows to choose an appropriate tactic considering the individual features of each patient.
\end{abstract}

Із розвитком та поширенням ендоскопічних та лапароскопічних технологій в хірургії дедалі більше патологій, що потребують інтервенційного підходу, лікують з їх застосуванням. Зокрема, пахвинна алогерніопластика, герніопластика уже більше 20 років у всьому світі виконується техніками лапароскопічної трансабдомінальної преперитонеальної пластики (ТАРР), ендоскопічної тотальної екстраперитонеальної пластики (ТЕР), трансінгвінальної преперитонеальної пластики (TIPP) та інтраперитонеальної алопластики “onlay” (IPOM). Перераховані методи є малоінвазивними та мають суттєві переваги над відкритими з огляду на кількість ускладнень, тривалість перебування в стаціонарі та післяопераційну якість життя. Однак питання вибору найбільш оптимальної техніки досі залишається відкритим, а отже, систематичний огляд та аналіз накопичених у літературі даних є необхідними для визначення стратегії хірургічного втручання, що забезпечить найкращі результати для пацієнта в ранньому та віддаленому післяопераційному періодах.

Проаналізовано публікації (ретро- та проспективних рандомізованих досліджень, системних оглядів та метааналізів) з 1985 до 2016 р. на тему лапаро- та ендоскопічних методів пахвинної алогерніопластики, доступних в базах PubMed, Cochrane та ResearchGate.

Перший досвід лапароскопічного лікування гриж був описаний Ralph Ger, завідувачем відділення гінекології в госпіталі Nassau в Мінеолі, Нью-Йорку. Він проводив операційне лікування 13 пацієнтам із пахвинними грижами, 12 з яких було виконано відкриту пластику, а 13-му Ger вирішив зробити операцію іншим способом - ввів лапароскоп через субумбілікальний доступ і закрив шийку грижового мішка скобою [1, 2, 3]. У 1989 р. гінеколог Сергій Богоявленський (Sergei Bogojavlensky) вперше використав методику plugand-patch (пробки і латки) при лапароскопічній пластиці пахових і стегнових гриж. Цього ж року Leonard Shultz, хірург Ебостського північно-західного госпіталю, вдосконалив дану методику i доповів перші серії лапароскопічної герніорафії, при яких він вводив сітчастий імплант через канал лапароскопа, розміщуючи його в ділянці грижі та дещо вище дефекту.

У 1990 p. Robert J. Fitzgibbons i Charles J. Filipi, професори хірургії в Клейгтонському університеті медицини, одночасно з Arregui винайшли новий метод - ТАРP (Transabdominal Preperitoneal Hernia Repair) [4]. Передумовами для розробки 
нових хірургічних втручань у пахвинній ділянці були такі фактори: більш глибоке розуміння анатомії та фізіології передньої черевної стінки та пахвинної ділянки, що стало можливим завдяки розвитку концепції mуоресtineal orifice, описаної H. R. Fruchaud у 1956 р., а також незадоволеність хірургів наявними на той час способами пластик пахвинних гриж. Тому Rene Stoppa в 1975 р. вперше запропонував операцію зміцнення вісцерального мішка гігантською сіткою (Giant Prosthetic Reinforcement of the Visceral Sac, GPRVS). Методика полягала в зануренні і розміщенні сітки-імпланта під пристінкову очеревину, на преперитонеальному рівні в mуоресtineal orifice. Теперішня ТАРР використовує ті ж самі принципи, тільки проводиться лапароскопічно [42-46].

Наступним етапом було використання Popp L. W. методу гідродисекції (за автором аквадисекції) очеревини, що стало передумовою для розвитку лапароскопічної герніопластики без розсічення очеревини [5]. Arregui M. E. i Phillips E. H. вперше запропонували техніку, яка не потребувала розсічення очеревини при пластиці задньої стінки пахового каналу [6, 7]. Дисекцію преперитонеального простору проводили під контролем лапароскопа, введеного в черевну порожнину. Dulucq у 1992 р. був першим хірургом, який провів ендоскопічну пластику грижі без введення лапароскопа в черевну порожнину (Transabdominal Extraperitoneal Plastic, TEP) [8, 9]. Ferzli G. S. i McKernan J. B. у подальшому популяризували дану техніку [10, 11].

На сучасному етапі розвитку хірургії малоінвазивні операції пластики гриж набули значного поширення, а саме трансінгвінальна преперитонеальна пластика сіткою (Transinguinal Preperitoneal Mesh-Plasty, TIPP), MINI (комбінація TEP і TAPP), інтраперитонеальна надапоневротична пластика сіткою (Intraperitoneal On-lay Mesh, IPOM), TEP, ТАРP. Найбільш поширеними серед них для лікування пахвинних гриж $є$ лапароскопічна трансабдомінальна преперитонеальна (ТАРР) та тотально екстраперитонеальна (ТЕР). Незважаючи на те, що дані техніки операцій стали рутинними в ряді герніологічних центрів більш ніж 20 років тому, досі залишається відкритим питання вибору тактики ТАРР або ТЕР, тому метою даного огляду $є$ аналіз літературних даних та порівняння вищевказаних методів.

Показанням до ТАРP і ТЕР є як унілатеральні, так і білатеральні грижі. Але якщо навіть тільки є підозра на наявність грижі з контралатеральної сторони або обтураторної грижі, то методом вибору є ТАРР $[12,13]$. Лапароскопічна методика має переваги при корекції рецидивних гриж після відкритої передньої пластики. Доведено, що при попередньо проведеній радикальній простатектомії (лапароскопічній або відкритій) виконання TAPР $є$ безпечним [14]. При ТАРР також можливе виконання симультанних операцій. Lehmann et al. вдалось одночасно провести ТАРP та холецистектомію [15]. Прийнятний час операції та коротший термін перебування в лікарні свідчать про те, що даний метод безпечний і $€$ адекватною альтернативою двом окремим операціям. Серед ускладнень у 8 пролікованих пацієнтів спостерігали 1 випадок гематоми та 1 випадок лихоманки (I рівень ускладнень за класифікацією Clavien-Dindo) [39]. Але при даній операції існує вищий ризик виникнення глибокої інфекції сітки та мешоми. Протипоказаннями для ТЕР і ТАРP є неможливість проведення загальної анестезії у зв'язку з тяжкими супутніми захворюваннями у пацієнта та раніше проведені операції в ділянці таза $[12,16]$.

Крива навчання міні-інвазивних методик істотно залежить від хірурга. Історично склалося, що спочатку вивчали методику ТАРР, а потім TЕР. Згідно з базою даних Кохранівського товариства за 2005 рік, у недосвідчених операторів (до 20 проведених операцій) час операції ТАРР складає 70 хв, а ТЕР - 95 хв. У досвідчених хірургів (30-100 операцій) тривалість була 40 і 55 хв відповідно. Певно, це пов'язано з тим, що при ТАРР хірург має більше місця і може одночасно спостерігати інтраперитонеальний та преперитонеальний простір, тоді як при ТЕР огляд відносно обмежений [16, 17].

Згідно 3 рандомізованими дослідженнями 2005 р. груп пацієнтів, яким виконували ТЕР $(\mathrm{n}=24)$ та ТАРP $(\mathrm{n}=28)$, спостерігали незначну перевагу в часі при ТАРР на 6 хв (рівень доказовості 3) [18]. Але згідно з даними Міжнародного товариства з ендохірургії гриж (International Endohernia Society) 2015 р., при ТАРP відмічається більша тривалість операції порівняно з ТЕР (рівень доказовості 1 В) [12, 18].

3 огляду на особливості техніки проведення, ТЕР може конвертуватись у ТАРР або відкриту операцію, а ТАРР конвертується тільки у відкриту. Конверсія ТЕР може відбуватися при великому розриві очеревини, а ТАРР - при неможливості адекватно підготувати преперитонеальний простір для розміщення сітки. В 1995-1998 рр. рандомізовані дослідження виявили значний рівень конверсії при ТЕР [19-21]. Нещодавні дослідження показують низький ступінь конверсії при ТЕР і ТАРР [22]. Конверсія залежить від здібностей хірурга і значно зменшується при отриманні достатнього досвіду. 
Стосовно витрат у двох рандомізованих дослідженнях не виявлено різниці у вартості між TEP i TAPP [22, 23].

Порівняльні дослідження демонструють в цілому низький рівень потенційно серйозних ускладнень незалежно від виду методики (рівень доказовості 2 А). Ушкодження внутрішніх органів, інфекції сітки частіше зустрічаються при ТАРР, більшість судинних ускладнень - пошкодження епігастральних судин - характерні для TEP [12, 13]. При ТЕР також можливий розрив очеревини 3 колапсом преперитонеального простору, що подовжує час операції і в деяких випадках вимагає конверсії [24]. Згідно з Kockerling et al., суттєвої різниці з огляду на інтраопераційні ускладнення між ТЕР і ТАРР виявлено не було [25]. Інфекцій, утворення гриж в місцях установки портів не відмічали. Bansal et al. виявили значно більшу частоту розвитку сероми у пацієнтів із ТЕР [26]. Набряк калитки набагато частіше зустрічався у групі ТАРР. Згідно з дослідженнями Kockerling et al., різниця в частоті післяопераційних ускладнень між ТЕР і ТАРP є значимою i пов’язана з більшим рівнем ускладнень при ТАРР у перші 30 днів після операції (3,97 \%, p<0,0001) [16]. Це пов'язано зі значною частотою виникнення сероми при ТАРP (TEP 0,51 \% і TAPP 3,06 \%; $\mathrm{p}<0,001)$. Фіксацією поперечної фасції до зв’язки Купера такером, що розсмоктується, можна запобігти розвитку набряку оболонок сім'яного канатика та яєчка у післяопераційному періоді [44, 45]. Вторинні кровотечі частіше розвиваються при застосуванні TEP (1,15 \%, p=0,03). Але дані щодо післяопераційних ускладнень не приводять до підвищення частоти повторних операцій, адже вказані післяопераційні ускладнення можна пролікувати консервативно [12].

Різниці в інтенсивності післяопераційного больового синдрому при ТЕР і TAPР у ряді досліджень не виявлено [27-29]. В іншому рандомізованому дослідженні сітку не фіксували при обох методиках, а при ТАРР зашивали очеревину. Це дослідження виявило більш інтенсивний больовий синдром на 1-й, 24-й годинах та 3-му місяці після операції [22]. Інше дослідження виявило більшу частоту післяопераційного болю при ТАРР порівняно з ТЕР на 1-му місяці, але на 6-му місяці суттєвої різниці не спостерігали [30]. У цьому дослідженні 18,1 \% ТАРР пацієнтів і 2,3 \% ТЕР пацієнтів мали більш ніж 10 такерів. Окрім того, при аналізі підгруп було виявлено, що у ТАРР пацієнтів при використанні менше 10 такерів інтенсивність больового синдрому була меншою. Про- ведені рандомізовані дослідження не виявили різниці в інтенсивності післяопераційного больового синдрому при різних методах фіксації, що виключає цей фактор впливу [31, 32]. Вік є важливим аспектом щодо можливостей виникнення хронічного болю, пацієнти молодшого віку частіше відмічають даний симптом (менше 54 років) [33].

У метааналізі Bracale et al. [15], а також Gass et al. [34] виявлено більший термін перебування в госпіталі пацієнтів із ТАРР порівняно з ТЕР (рівень доказовості 1 А). Інше дослідження такої різниці не виявило [26].

Стосовно рецидивів виявлено, що вони спостерігаються після 13 \% герніопластик [35]. Причини мають мультифакторіальну природу і бувають як технічні, так і нетехнічні [36]. Щодо технічних причин, то при ТЕР і ТАРР важливим аспектом $\epsilon$ розміщення імпланта в преперитонеальному просторі. Доведено, що при ТЕР за відсутності фіксації сітки показники рецидивів не змінюються, тому рекомендовано при дефектах менше 3 см не використовувати методи фіксації [37].

Техніка IPOM є простішою для виконання, оскільки протез фіксується безпосередньо до очеревини без її розкриття, але при даному методі спостерігали вищі рівні рецидивів та ускладнення, що включали кишкову непрохідність та формування фістул, тому дану техніку застосовують набагато рідше за TEP і TAPP [46]. Ї̈̈ можна виконувати у специфічних випадках, зокрема у пацієнтів, які перенесли простатектомію або операції на сечовому міхурі, чи при рецидивних грижах після імплантації двошарового сітчастого протеза.

Висновки. Методика ТАРР може використовуватись не тільки при білатеральних грижах, але і при підозрі на білатеральні та обтураторні грижі, защемлені грижі та при симультанних операціях. При даній техніці спостерігається менша крива навчання, нижчий рівень конверсій, ніж при ТЕР, але відмічається вищий ризик інтраопераційного ушкодження внутрішніх органів із розвитком сероми, набряку калитки. ТЕР забезпечує меншу тривалість операції у досвідчених хірургів, коротший термін перебування в стаціонарі та меншу частоту післяопераційних ускладнень, але для даної методики характерна більша кількість інтраопераційних судинних ушкоджень. Щодо витрат, інтенсивності та тривалості післяопераційного болю, а також відновлення фізичної активності, достовірної різниці при ТЕР і ТАРР не виявлено. Техніка IPOМ застосовується рідко через суттєво вищий ризик післяопераційних ускладнень та рецидивів, ніж при ТЕР і ТАРР. 


\section{СПИСОК ЛІТЕРАТУРИ}

1. Stern V. Laparoscopic Techniques for Hernia Repair: A History of Ups and Downs / V. Stern // General Surgery News. 2014. - Vol. 41, No. 3.

2. Ger R. The management of certain abdominal herniae by intraabdominal closure of the neck of the sac / R. Ger // Ann. R. Coll. Surg. Engl. - 1982. - No. 64. - P. 342-344.

3. Abdominal Wall Hernias: Principles and Management. / Robert Bendavid, Jack Abrahamson, Maurice E. Arregui [et al.] // Springer. - 2001. - P. 33-36.

4. Schultz L. Laser laparoscopic herniorrhaphy: a clinical trial preliminary results / L. Schultz, J. Graber, J. Pietrafitta [et al.] // J. Laparoendosc. Surg. - 1990. - Vol. 1, No.1. - P. 41-45. 5. Popp L. W. Improvement in endoscopic hernioplasty: transcutaneous aquadissection of the musculofascial defect and preperitoneal endoscopic patch repair / L.W. Popp // J. Laparoendosc. Surg. - 1991. - Vol. 1, No. 2. - P. 83-90.

6. Laparoscopic inguinal herniorraphy: techniques and controversies / M. E. Arregui, J. Navarrette, C. J. Davis [et al.] // Surg. Clin. North Am. - 1993. - Vol. 73, No. 3. - P. 513-527.

7. Phillips E. H. Laparoscopic preperitoneal inguinal hernia repair without peritoneal incision: technique and early clinical results / E. H. Phillips, B. J. Carroll, M. J. Fallas // Surg. Endosc. - 1993. - Vol. 7. - P. 159-162.

8. Dulucq J. L. Treatment of inguinal hernia by insertion of a subperitoneal patch under preperitoneoscopy / J. L. Dulucq // Chirurgie. - 1992. - Vol. 118. - P. 83-85.

9. Dulucq J. L. Treatment of inguinal hernia by insertion of a subperitoneal patch under preperitoneoscopy / J. L. Dulucq // Chirurgie. - 1992. - Vol. 4, No. 2. - P. 173-174.

10. Ferzli G. S. Extraperitoneal endoscopic inguinal hernia repair / G. S. Ferzli, A. Massad, P. Albert // J. Laparoscopic Surg. - 1992. - No. 6. - P. 281-286.

11. McKernan J. B. Laparoscopic repair of inguinal hernias using a totally extraperitoneal prosthetic approach / J. B. McKernan, H. L. Laws // Surg. Endosc. - 1993. - No. 7. - P. 26-28.

12. Update of guidelines on laparoscopic (TAPP) and endoscopic (TEP) treatment of inguinal hernia (International Endohernia Society) / R. Bittner, M. A. Montgomery, E. Arregui [et al.] // Surg. Endosc. - 2015. - Vol. 29, No. 2. - P. 289-321.

13. Jacob Brian P. The SAGES Manual of Hernia Repair / Brian P. Jacob, Bruce Ramslaw // Springer Science + Business Media New York. - 2013. - P. 197-202.

14. Claus C. M. P. Laparoscopic inguinal hernioplasty after radical prostatectomy: is it safe? Prospective clinical trial / C. M. P. Claus, J. C. U. Coelho, A. C. L. Campos [et al.] // Hernia. - 2014. - Vol.18, No. 2. - P. 255-260.

15. Bracale U. Which is the best laparoscopic approach for inguinal hernia repair: TEP or TAPP? A systematic review of the literature with a network meta-analysis / U. Bracale, P. Melillo, G. Pignata // Surg. Endosc. - 2012. - Vol. 26, No. 12. - P. 3355-3366.

16. Kingsnorth Andrew N. Management of abdominal hernias / Andrew N. Kingsnorth, Karl Le Blanc // Springer Science Business Media London. - 2013. - P. 271.

17. Transabdominal pre-peritoneal (TAPP) vs totally extraperitoneal (TEP) laparoscopic techniques for inguinal hernia repair / B. L. Wake, K. McCormack, C. Fraser [et al.] // Hernia. - 2005. Vol. 9, No. 2. - P. 109-114.

18. Does the approach to the groin make a difference in hernia repair? / O. Gunal, S. Ozer, E. Gurleyik, T. Bahcebasi // Hernia. - 2007. - No. 11. - P. 429-434.

19. Transabdomanal or totally extraperitoneal laparoscopic hernia repair? / R.V. Cohen, G. Alvarez, S. Roll [et al.] // Surg. Laparosc. Endosc. - 1998. - Vol. 8, No. 4. - P. 264-272.

20. Felix E. L. Laparoscopic hernioplasty. TAPP vs TEP / E. L. Felix, C. A. Michas, M. H. Gonzalez // Surg Endosc. - 1995. - Vol. 9. - No. 9. - P. 984-995.
21. Laparoscopic transperitoneal versus extraperitoneal inguinal hernia repair: a prospective clinical trial / R.Van Hee, P. Goverge, L. Hendrickx [et al.] // Acta. Chir. Belg. - 1998. - Vol. 98, No. 3. - P. 132-137.

22. Krishna A. Laparoscopic inguinal hernia repair: transabdominal preperitoneal (TAPP) versus totally extraperitoneal (TEP) approach: a prospective randomized controlled trial / A. Krishna, M. C. Misra, V. K. Bansal [et al.] // Surg Endosc. - 2012. Vol. 26, No. 3. - P. 639-649.

23. Comparison of the open tension-free mesh-plug, transabdominal preperitoneal (TAPP), and totally extraperitoneal (TEP) laparoscopic techniques for primary unilateral inguinal hernia repair: a prospective randomized controlled trial / K. Gong, N. Zhang, Y. Lu [et al.] // Surg. Endosc. - 2011. Vol. 25, No. 1. - P. 234-243.

24. Impact of peritoneal tears on the outcome and late results (4 years) of endoscopic totally extra-peritoneal inguinal hernioplasty / G. Muzio, K. Bernard, C. Polliand [et al.] // Hernia. - 2006. Vol. 10, No. 5. - P. 426-435.

25. Köckerling F. Has endoscopic (TEP, TAPP) or open inguinal hernia repair a higher risk of bleeding in patients with coagulopathy or antithrombotic therapy? Data from the Herniamed Registry / F. Köckerling, C. Roessing, D. Adolf [et al.] // Surg Endosc. - 2016. - Vol. 30, No. 5. - P. 2073-2081.

26. Bansal V. K. A prospective, randomized comparison of long-term outcomes: chronic groin pain and quality of life following totally extraperitoneal (TEP) and transabdominal preperitoneal (TAPP) laparoscopic inguinal hernia repair / V. K. Bansal, M. C. Misra, D. Babu [et al.] // Surg Endosc. - 2013. - Vol. 27, No. 7. - P. 2373-2382.

27. Transabdominal preperitoneal (TAPP) and extraperitoneal techniques for hernia repair / B. L. Wake, K. McCormack, C. Fraser, L. Vale // Cochrane Database Syst Rev. - 2005. - Vol. 25 (1). 28. Comparison of laparoscopic and open tension-free repair of recurrent inguinal hernias: a prospective randomized study / G. Dedemadi, G. Sgourakis, C. Karaliotas [et al.] // Surgical Endoscopy. - 2006. - Vol. 20, No.7. - P. 1099-1104.

29. Four arm randomized trial comparing laparoscopic and open hernia repairs / Y. Hamza, E. Gabr, H. Hammadi, R. Khalil // Int. J. Surg. - 2010. - No.8. - P. 25-33.

30. Prospective, comparative study of postoperative quality of life in TEP, TAPP and modified Lichtenstein repairs / I. Belyansky, V. B. Tsirline, D. A. Klima [et al.] // Ann. Surg. - 2011. Vol. 254, No. 5. - P. 709-724.

31. The impact of atraumatic fibrin sealant vs staple mesh fixation in TAPP hernia repair on chronic pain and quality of life: results of a randomized controlled study / R. H. Fortenly, A. H. Petter-Puchner, C. May [et al.] // Surg. Endosc. - 2012. - Vol. 26, No. 1. - P. 249-254.

32. Tam K. W. Outcomes of staple fixation of mesh versus nonfixation in laparoscopic total extraperitoneal inguinal repair: a metaanalysis of randomized controlled trials / K. W. Tam, H. H. Liang, C. Y. Chai // World J. Surg. - 2010. - Vol. 34. - No.12. - P. 3065-3074. 33. Medium-Term Recurrence and Quality of Life Assessment Using the Hernia-Specific Carolinas Comfort Scale Following Laparoscopic Inguinal hernia Repair / Omer Jalil, Ceri Rowlands, Angus Ruddle [et al.] // J. of Laparoendoscopic. - 2015. - Vol. 25, No. 6. - P. 477-480.

34. Gass M. TAPP or TEP? Population-based analysis of prospective data on 4,552 patients undergoing endoscopic inguinal hernia repair / M. Gass, V. Banz, L. Rosella [et al.] // World J. Surg. - 2012. - No. 36. - P. 2782-2786.

35. Kehlet H. Nationwide quality improvement of groin hernia repair from the Danish Hernia Database of 87,840 patients from 1998 to 2005 / H. Kehlet, M. Bay-Nielsen / Hernia. - 2008. No.12. - P. 1-7.

36. Burcharth J. The epidemiology and risk factors for recurrence 
after inguinal hernia surgery / Jakob Burcharth // Danish Medical Journal. - 2014. - Vol. 61, No.5. - P. 4846.

37. Koch A. Cody. Randomized Prospective Study of Totally Extraperitoneal Inguinal Hernia Repair: Fixation Versus No Fixation of Mesh / A. Cody Koch, M. Susan, R. N. Greenlee [et al.] // JSLS. - 2006 Oct-Dec. - Vol. 10, No.4. - P. 457-460.

38. Dindo D. Classification of Surgical Complications. A New Proposal With Evaluation in a Cohort of 6336 Patients and Results of a Survey / Daniel Dindo, Nicolas Demartines, Pierre-Alain Clavien // Ann. Surg. - 2004. - Vol. 240, No. 2. - P. 205-213.

39. Stoppa R. Unsutured Dacron prosthesis in groin hernias / R. Stoppa, J. Petit, X. Henry // Int Surg. - 1975. - Vol. 60, No. 8. - P. 411-413.

40. Wantz G. Giant prosthetic reinforcement of the visceral sac / G. Wantz // Surg. Gynecol. Obstet. - 1989. - Vol.169, No. 5. P. 408-417.

41. Mechanisms of hernia recurrence after preperitoneal mesh repair. Traditional and laparoscopic / A. Lowham, C. Filipi, R. Fitzgibbons [et al.] // Ann Surg. - 1997. - Vol. 225, No. 4. P. 422-431.
42. Maghsoudi H. Giant prosthetic reinforcement of the visceral sac: the Stoppa groin hernia repair in 234 patients / H. Maghsoudi, A. Pourzand // Ann. Saudi Med. - 2005. - Vol. 25, No. 3. - P. 228-232.

43. Open or laparoscopic preperitoneal mesh repair for recurrent inguinal hernia? A randomized controlled trial / G. Beets, C. Dirksen, P. Go [et al.] // Surg Endosc. - 1999. - Vol. 13, No.4. - P. 323-327.

44. European Hernia Society guidelines on the treatment of inguinal hernia in adult patients / M. P. Simons, T. Aufenacker, M. Bay-Nielsen, J. L. Bouillot // Hernia. - 2009. - Vol. 13, No. 4. - P. 343-403.

45. Use of human fibrin glue (Tissucol) versus staples for mesh fixation in laparoscopic transabdominal preperitoneal hernioplasty: a prospective, randomized study / F. Lovisetto, S. Zonta, E. Rota [et al.] // Ann Surg. - 2007. - Vol. 245, No. 2. - P. 222-231.

46. Prasad P. Laparoscopic ventral hernia repair: a comparative study of transabdominal preperitoneal versus intraperitoneal onlay mesh repair / P. Prasad, O. Tantia, N. M. Patle [et al.] // Journal of Laparoendoscopic \& Advanced Surgical Techniques Part A. -2011 , No. 21. - P. 477-483.

Отримано 03.05.16 